\title{
Diversify Your Family's Risks by Returning to Its Entrepreneurial Roots
}

\author{
David Deeds (University of St. Thomas)
}

KEYWORDS: Entrepreneurship, Management, Family Business.

Family enterprises are the backbone of the world's economy and critically important to the economic growth and development of every nation. On average, they outperform publicly owned non-family firms because family control gives them a long-term perspective on investments and performance, stability in leadership and values, and strong organizational culture and norms.

But even the most successful family businesses face two critical challenges: diversifying their wealth and preparing the next generations to succeed. Rejuvenating the family's entrepreneurial spirit can accomplish both. It can protect the core of a family's wealth by diversifying the family business across markets, geographies and technologies, reducing the product, market, country and location risks to the family's wealth. It also prepares the next generation for leadership.

However, family business owners seeking to diversify and grow their wealth don't often go this route. Instead, they may withdraw funds from the core family business and reinvest it elsewhere, or acquire another company to expand into new products or markets. Each of these options creates significant risks and challenges.

\section{The Problem with Reinvestment}

Family business owners are limited in their ability to diversify the wealth of the family because the bulk of the wealth is retained within the business. This concentration of wealth within a single firm leaves the family vulnerable because all of its risk is in one place.

Families often turn to traditional financial markets to achieve financial diversification. This means taking wealth from the business and investing it in stocks, bonds, hedge funds, real estate, and other assets -- but cash is fungible and may get easily diverted to living expenses, housing, vacations, etc.

\begin{abstract}
Extracting cash can pose two problems if not well managed. The first is that family members may come to expect an increased cash flow from the business, which may or may not be sustainable. In hard times these expectations may create a difficult choice of either disappointing family members or draining the funds required to keep the business secure. This can lead to friction among family members, which can disrupt the business and threaten its future.
\end{abstract}

The second problem is that it drains funds that could be used to fund growth opportunities, strengthen existing positions or provide a buffer during hard times. Unless judiciously applied, removing wealth from the family business to diversify the family's wealth can lead to underinvestment in the existing firm, shortchanging investment in operations, $R \& D$ and marketing. Over time this weakens the firms' competitive position. Extracting capital may in fact increase the risk to the family's wealth, by increasing a firms' business risk and substantially increasing the family's overall risk.

In short, this option provides very few benefits besides diversification. While the relatives managing the family's outside investments may learn more about finance, they won't learn about management, operations, sales and marketing, and other skills that they will need to build on the family's previous success. And the firm itself could end up weaker and unable to grow and invest in potentially profitable opportunities. This frequently leads to the erosion of the family business's competitive position.

\section{The Drawbacks of Acquisitions}

Acquisitions are another potential solution to the issue of under-diversification. The family firm can leverage its wealth and competitive advantage by buying another firm that expands markets, products and/or market power. When acquisitions go well they provide profitable growth opportunities and increased margins via
Copyright (C) 2022 The Authors. Entrepreneur \& Innovation Exchange is published at EIX.org. This is an open access article under the terms of the Creative Commons Attribution-NoDerivs License, which permits use and distribution in any medium, provided the original work is properly cited and no modifications or adaptations are made. View EIX.org Authorship Terms at https://eix.org/terms
FamilyBusiness 
synergies between the family enterprise and the acquired firm. Acquisitions also diversify the risk to the family's wealth by decreasing the business' dependence on a few products or markets.

However, acquisitions are extremely challenging and historically have had a low rate of success.

They typically cost much more than the initial estimates, and integrating two organizations is almost always much more difficult and longer than expected. Families often don't think through the possible negative impact of the acquisition on the operations of the core family enterprise. Merging systems, processes and cultures can be both difficult and disruptive. Follow-on costs in terms of capital, time and attention can detract from the growth of the original business. Bringing in a new culture can substantially alter the existing culture, for better or worse. Acquisitions are not low risk undertakings[1]

(denied:applewebdata://7AD0F7A8-2C63-480E-A70ACB1594A3FF32\#_ftn1) .

Even a successful, fully integrated acquisition can create considerable added risk in the near term. And a failed acquisition poses a substantial threat to the health of the family's core business and the wealth stored in that business. Acquisitions can provide the managerial training and challenges that prepare the next generation to lead, but given the size of the investment, the high risk of failure, and the stakes, this is not a task for novices or the ill-prepared. Acquisitions are difficult and require substantial managerial skill, experience and expertise, and don't teach the next generation how to be entrepreneurial and innovative.

\section{The Enterprising Family Solution}

While reinvestment and acquisitions are common strategies, another often-overlooked alternative can lead to lower risk, the creation of substantial new wealth, and the perfect opportunity to train, evaluate and incorporate the next generations into the family business. That strategy is rejuvenating your family's entrepreneurial culture and transitioning from a business family to an enterprising family.

Across generations a business family works to create a strong, stable business. It keeps the trains running on time, refines the product and service, creates a strong financial structure to support the business, hits sales targets, achieves financial goals, increases efficiencies and generates consistently strong profits and cash flows.

The family's mindset shifts from the entrepreneurial mindset during the founding years to a managerial mindset over the succeeding generations, perhaps even during the founder's tenure. The family becomes a business family rather than an entrepreneurial enterprising family.

Shifting back to an enterprising family mindset means the family continues to nurture the core family business while at the same time returning to its entrepreneurial roots. Remember that every family business began with an entrepreneurial act: the founding of the business by the first generation. The solution to both wealth diversification and the challenge of preparing the next generation is to once again become an enterprising family.

Being an enterprising family does not mean pursuing hare-brained schemes, taking undue risks or indulging the next generations' business visions without questioning. It means returning to the tools and techniques being used by entrepreneurs today, or relearning them. These include lean startup techniques, hypothesis testing and options logic; training the next generation to be entrepreneurs and the current generation to act like venture investors; and embracing processes, rigor and discipline.

\section{How to Begin}

Here are some steps on the path to becoming an enterprising family.

- Shift at least part of the family's focus from utilizing existing resources and hitting sales, revenue and profit targets to seeking and exploiting new opportunities. Ask not what is on the shelf, but what's not on the shelf. Seek out gaps between what is currently being offered and what is possible. Develop the entrepreneurial mindset of the family members.

- Seek and expect ideas for new products/services from next generation. Discuss it at family meetings and over the kitchen table. Ask them for new ideas. Begin this early and do it often.

- Establish a process within the family structure that reviews new ideas, provides small amounts of resources (time and money) to further their 
development, and monitors and continuously evaluates any ideas funded by the enterprising family. This process should include requirements for presentations, so they are more than just brainstorming exercises. If you want funding, prove the potential value of the idea. At the very least l'd suggest requiring the family entrepreneur to complete a Business Model Canvas. I suggest reading up on lean startup and hypothesis-driven entrepreneurship[2] (denied:applewebdata://7AD0F7A8-2C63-480EA70A-CB1594A3FF32\#_ftn2) .

- Recognize that there is such a thing as a constructive failure, and that most ideas will fail. The key is to fail early, often and cheaply. If it isn't working, end it.

- The core of the family must act like venture capitalists: ruthless but constructive in their evaluation of the proposals, demanding that those who are funded meet milestones and achieve heroic results, requiring that the next generation act like entrepreneurs and do more with less.

- The family must nurture the entrepreneurial spirit of the next generation through training, encouragement, mentoring and teaching them about the entrepreneurial success stories of the prior generations.

- The family must make difficult decisions based on the quality of the business without being clouded by family ties. This is why structures, processes and measurable milestones are needed. It is often helpful to bring in outside evaluators to provide additional objective eyes in the evaluation process.

\section{A Mandate for the Next Generation}

Becoming an enterprising family also requires the next generations to rise to the challenge and seek out opportunities for growth and profit. They need to create well-developed plans, business models and presentations for their ideas that would impress a Silicon Valley venture capitalist. They must do the research before initiating the venture. They can no longer depend on the indulgence of their parents and grandparents, but must up their game to meet the standards of professional venture investors. This will push them to become entrepreneurs who seek and exploit opportunities through creativity, vision, and lots of hard work. Being an entrepreneur is the hardest job in the modern economy. It demands that you do more with less. It accepts no excuses and demands superior execution.

At this point you may be wondering whether becoming an enterprising family creates the same risks for family firms as expanding through acquisitions. The answer is no, if well executed. Entrepreneurs and venture capitalists minimize risk by applying real options reasoning. They minimize initial investments, demand that milestones be hit before future funding, and end the underperforming projects quickly. If the entrepreneur estimates that $\$ 5$ million is needed for a venture, no investor will provide that much. Rather, they might provide $\$ 5,000$ and specify what must be accomplished before coming back.

An entrepreneur minimizes initial investments because they are the highest risk and most expensive capital. The apply lean startup techniques like rapid prototyping, customer discovery interviews and minimum viable products that defer risk and minimize initial investments. They are forced by the markets to continually prove themselves by achieving outcomes such as patenting, prototyping the product, getting the initial customer, and creating a profitable and scalable business model in order to gain the resources they need. Commitments of resources are staged and additional commitment requires that outcomes be achieved and milestones be met.

\section{Renewed Excitement}

What is the outcome of the transition from a successful business family to a successful enterprising family? As we've mentioned, it diversifies business risk as the family's wealth is spread across markets, products and locales, and continues to seek out new opportunities for profitable growth. It also develops the next generation of leaders, who are being given a chance to create/contribute something of their own.

Finally, a return to a family's entrepreneurial roots can instill lasting dynamism and bring excitement back into the family business and the family culture. Relatives can appreciate and celebrate the entrepreneurial roots of their business and the entrepreneurial spirit of their family. 
[1] (denied:applewebdata://7AD0F7A8-2C63-480E-

A70A-CB1594A3FF32\#_ftnref1) King, D. R. (2022).

Family Business Restructuring: A Review and Research

Agenda. Journal of Management Studies, 59(1), 197-235.

[2](denied:applewebdata://7AD0F7A8-2C63-480E-

A70A-CB1594A3FF32\#_ftnref2) Suggested books on lean startup include Ries, E. (2011). The lean startup: How today's entrepreneurs use continuous innovation to create radically successful businesses. Crown Business. Also Osterwalder, Alexander, and Yves Pigneur. Business Model Generation. John Wiley \& Sons, 2010. 